\title{
Bilingual Language Processing
}

\author{
Timothy Desmet* and Wouter Duyck \\ Ghent University
}

70

\section{Abstract}

This article provides an overview of the psycholinguistic research concerning the processes and representations that bilinguals use while processing language. We review the lexical, semantic, and syntactic levels of bilingual processing. The main conclusion from this review is that the different languages of bilinguals strongly influence each other during processing. Therefore, we end with a brief overview of some recent research about how bilinguals are able to keep this interference under control. Throughout the review we will point towards promising future developments.

\section{Introduction}

Without bilinguals the world would be a modern Tower of Babel. Everybody has experienced the great discomfort of having to rely on primitive methods of communication, such as gesturing, when in a country where nobody speaks a language you know. This prompted Steve Martin to say in despair 'Boy, those French, they have a different word for everything!' Luckily, about half of the world's population has some knowledge of more than one language (Grosjean 1982, p. vii). Widespread bilingualism is not a privilege of 'developed' Western countries such as notoriously bilingual Canada (French-English), Belgium (Dutch-French), Wales (Welsh-English), or Cataluña (Catalan-Spanish). In Cameroon, for example, there are two official languages, four 'lingua francas', and 285 dialects. More than half of the population speaks three or more of these languages (Bamgbose 1994). From the above and following the literature, it will be clear that the term 'bilingual' in the present review does not only apply to people who speak two languages equally well. Instead, 'Bilingualism is the regular use of two (or more) languages, and bilinguals are those people who need and use two (or more) languages in their everyday lives' (Grosjean 1992, p. 51). Following the research literature, we will use this definition of bilingualism in the present review.

In contrast with the omnipresence of the phenomenon, psycholinguistic research on bilingualism has only started quite recently. Most classical models of language processing are exclusively monolingual. They do not allow cross-lingual interactions in monolingual language processing by bilinguals 
(e.g. word recognition, McClelland \& Rumelhart 1981; word production, Levelt 1989). However, as will be clear from the present review, it is not possible during speaking or listening for people to 'switch off' their native language or even their second language and process language in a purely monolingual mode. Interactions between languages have been observed at all representational levels of language, even when people were tested in purely monolingual language contexts.

In the present review, we will briefly point out the main research questions and empirical findings in bilingual psycholinguistic research. We will also briefly discuss the main theoretical models that have been proposed for bilingual processing. Of course, the discussion of these models is of a rather more technical level. However, we tried to make the article readable even if the reader decides to skip the parts devoted to the theoretical models. Because this overview is aimed at a general audience, in each section we will also provide pointers to more specific and detailed reviews of the discussed domain.

This review will be organized according to the different levels of language representation. We will start at the word level. In most models of word processing, a distinction is made between form representations, and their underlying meaning. In the present article, form representations will be labeled lexical representations. These form representations can be of an orthographic nature (having to do with the writing system, e.g. the word 'cat' is written with the letters ' $c$ ', 'a', 't'), or of a phonological nature (having to do with the speech sound system, e.g. the word 'cat' is pronounced as $/ \mathrm{kxt} /$ ). All meaning-related representations will be labeled semantic representations. At the word level, we will subsequently discuss lexical (orthographic/phonological) and semantic representations, and the mappings between these two. At the sentence level, we will have a look at the recent research on bilingual syntactic representations. To conclude, we will discuss some key studies on language switching, a recent line of research that can shed more light on how bilinguals are able to control the constantly interacting representations of their languages.

\section{Lexical Representations}

In essence, being bilingual means having more than one lexical representation to express the same meaning. English-French bilinguals (bilinguals whose native language is English and whose second language is French) for instance can refer to the barking pet by the English word dog or by the French word chien [dog]. The most simple and intuitively appealing theory about these lexical representations would probably be that bilinguals have two separate lexicons (mental dictionaries): one lexicon that contains all the words of their native language (L1) and another lexicon that contains the words of their second language (L2). Surprisingly, a lot of evidence has been gathered against this hypothesis. Many studies have found that lexical representations 
from the first language are accessed during processing words from the second language and vice versa. We will briefly discuss the key findings on this issue (for more extensive reviews, see Dijkstra \& Van Heuven 2002; Kroll \& Dussias forthcoming).

\section{ORTHOGRAPHY}

Most of the research on this issue has focused on orthographic lexical representations (representations that are related to how a word is written) and the cross-lingual interactions between these orthographic representations. Van Heuven, Dijkstra and Grainger (1998) started from the common finding in monolingual research that the speed with which people can recognize a word depends on how many orthographic neighbors that word has. The 'neighborhood size' of a word is the number of words that can be created by replacing one letter of that word. For instance, whereas the word 'chair' has a neighborhood size of two (only 'chain' and 'choir' can be formed by replacing one letter of the word 'chair'), the word 'car' has a neighborhood size of nineteen ('bar', 'far', 'war', 'ear', 'cab', 'cat', 'cap', etc.). Van Heuven et al. found that word recognition depends on the neighborhood size of the word in both languages. So the speed with which Dutch-English bilinguals recognized an English word like farm did not only depend on the number of English neighbors (e.g. firm, fart), but also on the number of neighbors this English word has in Dutch (e.g. darm [colon], faam [fame]). This strongly suggests that lexical orthographic representations from one's native language are active during word recognition in one's second language.

Another line of evidence comes from studies investigating the recognition of inter-lingual homographs, which are words that are written the same way in both languages but mean different things. For instance, the word room refers to a part of a house in English, but in Dutch the word room means 'cream'. Dijkstra, Timmermans and Schriefers (2000) presented DutchEnglish bilinguals with words and asked them to press a button only if the word was a word in English (a lexical go/no-go task). Participants responded slower to inter-lingual homographs (such as room), which also exist in Dutch, than to control words, which only exist in English (such as chair). Apparently, the Dutch homograph reading (room as 'cream') was activated and it interfered with the recognition of English words.

Further evidence for cross-lingual interaction at the orthographic level comes from the cognate facilitation effect. Cognates are words that mean the same thing in both languages and also have full or partial form overlap across languages (e.g. Dutch-English, film-film; English-Spanish, cross-cruz; Dutch-German, sterven-sterben [to die]). Even in monolingual language contexts that do not require activation of more than one language, cognates are processed faster than control words in a wide range of word recognition and word production tasks (e.g. lexical decision, Caramazza \& Brones 1979; Cristoffanini, Kirsner \& Milech 1986; naming, Schwartz, Kroll \& Diaz forthcoming; word translation, de Groot, Dannenburg \& van Hell 1994, 
Sanchez-Casas, Davis \& Garcia-Albea 1992; picture naming, Costa, Caramazza \& Sebastian-Galles 2000, Costa, Santesteban \& Cano 2005; and progressive demasking, Dijkstra, Grainger \& Van Heuven 1999). Interestingly, using cognates with only partial form overlap (e.g. Dutch-English, banaan-banana), Van Hell and Dijkstra (2002) showed that this cognate facilitation effect could be found even when no words from the second language were presented at all in the task (not even homographs or identical cognates). This offers strong evidence for an influence of the second language on processing of the native language. Moreover, Lemhöfer, Dijkstra and Michel (2004) showed that such cross-lingual facilitation effects may even accumulate over multiple languages: using Dutch-English-German trilinguals, they reported faster responses to German words that are cognates with both Dutch and English (wind, park, film, tunnel, etc.) than for German words that are cognates only with Dutch (schuld [guilt], pech [bad luck], kunst [art], etc.).

\section{PHONOLOGY}

In most of the cognate studies above, cross-lingual form interactions are often complex interactions of orthographic and phonological information (see, for example, Schwartz et al. forthcoming). In most languages, orthographical overlap (letter information) is obviously confounded with phonological overlap (speech sound information). One piece of suggestive evidence that phonology has an independent role comes from Gollan, Forster and Frost (1997). They found that Hebrew-English bilinguals were faster to recognize Hebrew words if they had seen the English translation of that word just before. This priming effect was larger when prime and target were cognates. This cognate effect can only be attributed to the similar phonology, because orthography is completely different for English and Hebrew (different script and opposite reading direction).

Only a few studies have tried to investigate phonological cross-lingual interactions more directly. For instance, Brysbaert, Van Dyck and Van De Poel (1999; see also Duyck et al. 2004) showed that bilinguals are faster to recognize words from their second language if these words are primed by non-words that sound like that word (pseudohomophones) if they are pronounced as in the native language. For instance, Dutch-French bilinguals will be faster to recognize the French word sourd [deaf] if they saw the non-word soer just before, which sounds like the French sourd if it is pronounced in Dutch. Using the same stimuli, but with French-Dutch bilinguals this time, Van Wijnendaele and Brysbaert (2002) showed that the influence across languages also goes in the opposite direction: they found that L2 pseudohomophone primes (soer which sounds like sourd if pronounced in their second language) also facilitate the processing of L1 targets (sourd). This strongly suggests that access to phonological representations is not selective with respect to language.

Similar findings were recently obtained by Duyck (2005), who showed that phonological representations from a non-target language may be (c) 2007 The Authors Language and Linguistics Compass 1/3 (2007): 168-194, 10.1111/j.1749-818x.2007.00008.x Journal Compilation (c) 2007 Blackwell Publishing Ltd 
activated fast and strongly enough to pre-activate target translations. For instance, Dutch-English bilinguals were faster to recognize a word in their second language (e.g. back) when they had seen a pseudohomophone of the translation of that word in their first language (e.g. ruch, which is a non-word that if it is pronounced in Dutch sounds like rug [back]). This was true even in the opposite direction: Dutch-English bilinguals were also faster to recognize a word in their native language (e.g. touw [rope]) when they had seen a pseudohomophone of the translation of that word in their second language (e.g. roap, which sounds like rope when pronounced in English). Even more intriguing, a similar priming effect was found for the recognition of L2 words (e.g. church) with pseudohomophone words in their first language that were not translations, but which were merely semantically related (e.g. pous, which sounds like paus [pope] in Dutch). Again, these findings suggest that bilinguals rapidly access phonological representations from their second language when they are processing their first language, and vice versa.

Finally, Jared and Kroll (2001) showed that people were significantly slower to pronounce words in their second language when a part of that word could be pronounced in a different way in their first language, even when the experiment was entirely run in their second language. For instance, French-English bilinguals took longer to pronounce the English word bait than the English word bump, because bait contains ait, which is pronounced differently in French, whereas the word part ump is not used in French. The opposite effect of second language words on their first language was only obtained if participants had named a block of second language words prior to the experiment.

In line with the above evidence for interactions between orthographic lexical representations between the different languages of bilinguals, these studies show that also phonological lexical representations from the first language may be accessed when reading in their second language (and to a certain extent, the other way around). For a recent, more detailed discussion of this topic, we refer to Duyck (2005).

\section{AUDITORY WORD PROCESSING}

Whereas the emphasis of the psycholinguistic research and the above overview is on visual word recognition (reading), it should be noted that these findings are not without analogues in the auditory domain (listening). For example, Weber and Cutler (2004) observed that Dutch-English bilinguals hearing words in English (e.g. desk) made longer eye fixations on pictures with names in Dutch that were phonologically related to the English word (e.g. a picture of a lid, for which the name in Dutch, deksel, starts with the same sounds). However, the opposite effect (influence from English names for pictures on Dutch words) was not found: Dutch-English listeners did not look longer at a picture of a desk when they heard the Dutch word deksel. These results suggest that interference from phonological representations from the other language is larger when processing one's second (c) 2007 The Authors Language and Linguistics Compass 1/3 (2007): 168-194, 10.1111/j.1749-818x.2007.00008.x Journal Compilation @ 2007 Blackwell Publishing Ltd 
language than when processing one's native language. Similar findings were reported by Marian, Spivey and Hirsch (2003), who found that RussianEnglish bilinguals instructed in English to 'pick up the marker' often looked at a stamp, because its Russian translation (marka [stamp]) has phonological overlap with the English spoken word.

It should be noted, however, that recent research has shown that the phonological overlap between the words in both languages has to be very precise in order to interfere with each other. Ju and Luce (2004) showed that even very subtle differences in acoustic-phonetic information can reduce the parallel activation of words in the two languages. They showed that Spanish-English bilinguals often looked to a picture of pliers when they heard the word 'playa', but only when the word 'playa' was pronounced with the 'pl' sound of 'pliers' and not with the 'pl' sound of 'playa' (which they spliced in with the aid of a computer). So, even this fine-grained and subtle difference in phonetics was enough to stop interference from Spanish phonology with English words.

In the near future, it will be interesting to see whether the larger body of evidence from the visual domain will further extend to the auditory domain.

\section{WORD RECOGNITION IN SENTENCE CONTEXT}

In all of the studies above, word recognition is always examined out-of-context. In most studies, participants in the experiment were asked to pronounce or recognize single words in isolation (presented in the middle of a computer screen). One of the key research questions in future psycholinguistic bilingualism research will be to what extent the findings of lexical interaction between languages also applies if words are embedded in sentences, as in everyday language. It is possible that bilingual readers use the language of the sentence as a strong cue for lexical search for words appearing in that sentence, much in the way semantic sentence context is used to generate expectations about upcoming words (e.g. Schwanenflugel \& Lacount 1988). This would imply that the different languages of a bilingual may interact with each other when words are presented in isolation (as in the studies above), but that a non-target language virtually has no effect on word recognition when words are presented in sentences.

At present, the few studies that have directly assessed this issue (Duyck, Van Assche \& Hartsuiker forthcoming; Elston-Guttler, Gunter \& Kotz 2005; Schwartz \& Kroll 2006) seem to suggest that the influence of the sentence context on cross-lingual interference is rather limited. At least in comprehension, it seems that even when the words appear in sentences, there is still considerable interaction between the two languages of bilinguals. The cognate facilitation effect described above survives when target words are embedded in sentences: even when bilinguals read sentences in their second language, words appearing in those sentences (e.g. banana in English) are recognized faster if they have a cognate translation in their first language 
(e.g. banaan in Dutch). So, simply presenting words in a sentence does not eliminate the interference of lexical information from the other language. However, semantic sentence context effects do affect cross-lingual activation transfer. For instance, Schwartz and Kroll (2006) showed that the cognate facilitation disappeared if the cognate words in the second language were very predictable from the meaning of the sentence. It is clear from this brief discussion, that much more research is needed to find out whether the parallel activation of the lexical representations of the two languages of bilinguals also holds in more natural language processing.

\section{THE BILINGUAL INTERACTIVE ACTIVATION MODEL}

During the last decade, probably the most influential inspiration for the above research on lexical autonomy has been the Bilingual Interactive Activation (BIA) model of Dijkstra and Van Heuven (e.g. Dijkstra et al. 1999; for its successor, BIA+, see Figure 1, Dijkstra \& Van Heuven 2002). BIA constitutes an extension of the interactive activation model of monolingual visual word recognition (e.g. McClelland \& Rumelhart 1981), containing feature, letter, word, and language nodes.

In the model, L1 and L2 words are represented in an integrated lexicon. The model assumes that word recognition is fundamentally non-selective with respect to language, as word activation is affected by competing representations from both languages. Because BIA+ does not contain top-down connections from the language nodes to the lexicon, all effects of language context and stimulus list composition (e.g. see earlier, Dijkstra et al. 2000) are dealt with by a task schema system, which only receives input from the non-selective word identification system. Because BIA+ is an implemented computational model, its main merit is that its clear and testable predictions have driven research about the non-selective lexical access claim. In general, research has shown that the basic architecture of the model captures bilingual word recognition very well. However, because only the orthographic representations are fully implemented at present, one of the interesting issues in future bilingual modeling will be to see the development of the remaining parts of BIA+'s word-identification system (phonological and semantic representations) and of its task schema system. It will be a challenge to capture the sometimes complex (cross-lingual) interactions of orthographic, phonological, and semantic representations and their modulation by linguistic and semantic sentence contexts (see, for example, the above interaction effect of sentence constraint with cognate status obtained by Schwartz \& Kroll 2006). In this view, it is interesting to note that the first steps towards future development of BIA+ have already been taken. Thomas andVan Heuven (2005) describe a localist connectionist model, called SOPHIA (Semantic, Orthographic, PHonological Interactive Activation model), which is essentially a fully implemented version of BIA+'s word identification system, including orthography, phonology, and semantics, but without the task schema system. SOPHIA has already been tested on a wide (c) 2007 The Authors Language and Linguistics Compass 1/3 (2007): 168-194, 10.1111/j.1749-818x.2007.00008.x Journal Compilation @ 2007 Blackwell Publishing Ltd 


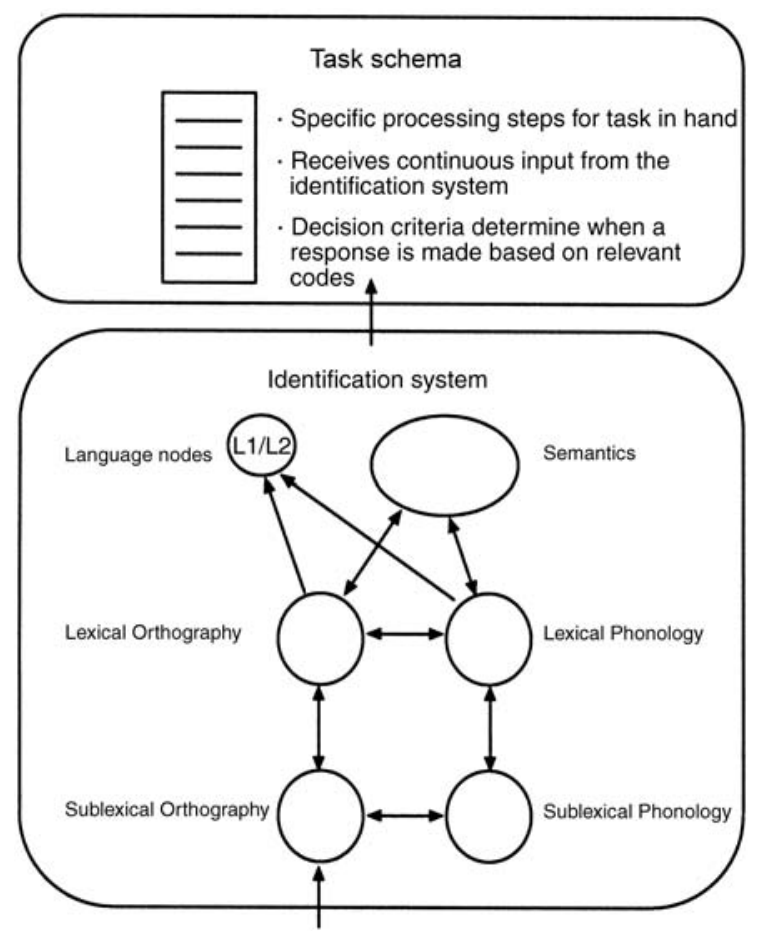

Fig. 1. The BIA+ Model (Dijkstra \& Van Heuven 2002). Reproduced with permission of Cambridge University Press.

range of findings from monolingual language processing, and is currently being applied to bilingual phenomena (Thomas \& Van Heuven 2005).

\section{Semantic Representations}

Let us start this section with the same statement: bilinguals have more than one lexical representation to express meaning. But what about meaning? Is every form representation mapped onto a different semantic representation or not? Unlike lexical representations (words), semantic representations (concepts) do not differ much across languages. Dog in English refers pretty much to exactly the same concept as hond [dog] does in Dutch. Therefore, it would not be very economical to have separate representations of (almost) identical meanings. In contrast with the lexical level, the intuitive assumption thus seems to be that bilinguals have only one store with concepts, rather than two separate stores (one for the meanings from their first language and another one for the meanings from their second language). Most psycholinguistic research has confirmed this intuitive assumption. In the present section, we discuss a few main findings and the main theory about this issue. For more extensive reviews of semantic representations in bilinguals, we refer to Francis $(1999,2005)$. 
First, studies have shown that semantic processing in one language may interfere with processing in the other language. For instance, Fox (1996) showed that bilinguals are slower to recognize words in their second language when semantically related words in their native language were presented as irrelevant distracter stimuli on previous trials. For instance, participants needed more time to indicate that sel [salt] is a French word when they had seen the word pepper before in a completely unrelated task (judging whether an Arabic numeral is even or uneven). A similar negative priming effect was also observed when those bilinguals had to react to native language words that appeared in the middle of the screen (e.g. salt) and ignore the second language translation next to it (i.e. sel [salt]). In word production, studies have consistently shown that picture naming is disrupted when semantically related words are also presented but need to be ignored, regardless of the distracter word's language (e.g. Costa, Miozzo \& Caramazza 1999; Hermans et al. 1998).

Second, it has been shown that the recognition of a word is facilitated when it is preceded by a tachistoscopically (very briefly) presented word, which is a semantic associate in the other language. For instance, de Groot and Nas (1991) found that Dutch-English bilinguals were much faster to recognize the English word girl not only after the English prime word boy but also after the Dutch prime word jongen [boy] (see also Grainger \& Frenck-Mestre 1998). This effect when the semantic associate is from the other language is about $75 \%$ the size of the effect observed when the semantic associate is in the same language (Francis 1999).

Third, using functional magnetic resonance imaging, a technique to measure neural activity in the brain, Illes et al. (1999) measured the brain activity of proficient bilinguals performing a semantic categorization task: English-Spanish bilinguals were presented with single words and had to indicate whether these words were abstract (e.g. peace) or concrete (e.g. shoe). The idea behind this task is that participants have to activate the meaning of the words in order to be able to perform the task, i.e. they have to think about what shoe means in order to indicate whether it is a concrete or an abstract word. The authors showed that the brain activity related to activating the meaning of words was exactly the same independent from whether the words were from their native language or from their second language. In both languages, there was enhanced activation in the left inferior prefrontal cortex, which is in line with findings from previous monolingual studies about semantic activation.

\section{THE DISTRIBUTED FEATURE MODEL}

Because there now is a large consensus that both L1 and L2 words access a common semantic system, the main question here probably needs to be which factors influence the nature and the degree of overlap of these semantic representations. A good model to build upon is the Distributed Feature 
Model (DFM) of de Groot and colleagues (e.g. see Figure 2, de Groot 1992, 1994; van Hell \& de Groot 1998).

A basic assumption of the DFM is that the meaning of each translation equivalent must not be exactly the same. Indeed, bilinguals often have the feeling that a word (or expression) in one language does not have a translation equivalent with exactly the same meaning. For instance, studying SpanishEnglish bilinguals, Altarriba (2003) showed that emotion words are slightly differently conceptualized in English than in Spanish. In Spanish, emotion words are more readily contextualized to a specific episode than in English. To describe the relative overlap in meaning representations for different types of concepts in the DFM, word meanings are represented as sets of distributed features in the model. The overlap in meaning, indexed by the number of shared features, depends on the type of word being represented. One of the main tenets of the distributed feature model is that concrete words (e.g. ball) have more similar meanings (indicated by a larger feature overlap) across languages than abstract words (e.g. justice). Evidence for this claim comes, for example, from van Hell and de Groot (1998), who showed that concrete words yielded more similar word associations across languages than abstract words. For more details about the model and its predictions, we refer to de Groot and colleagues. Because the DFM has yielded less research during the last decade than for example BIA+ has, it will be interesting to see whether the DFM may still be fully implemented and developed to a greater level of detail. Also, because the DFM is restricted to word-level semantic representations, it is still an open question to what extent it can account for the interaction of semantic sentence constraints effects, such as the one discussed in the previous section.

\section{Mapping Lexical Representations onto Semantics}

Concurrently with the above research on the architecture and nature of lexical and semantic representations, one of the central questions in bilingual research has been how the lexical representations are mapped onto their underlying semantic representations. Typically, this question has been assessed by studying semantic effects in the word translation task, where participants are asked to translate a word from one language into the other language as fast as possible. The dominant view in the literature about this issue has been provided by the Revised Hierarchical Model (RHM) of Kroll and colleagues (see Figure 3, Kroll \& Stewart, 1994; Kroll \& de Groot, 1997). As can be seen in Figure 3, this classical model is quite vague about the nature of the lexical and semantic modules, which are basically just black boxes.

Instead, the main assumptions of the model concern the way in which these modules are mapped onto each other. As can be seen in Figure 3; the RHM is asymmetric with respect to the strength of its lexico-semantic connections. Because the connections from the L2 lexicon to the L1 lexicon are stronger than from the L2 lexicon to the semantic system, the model 


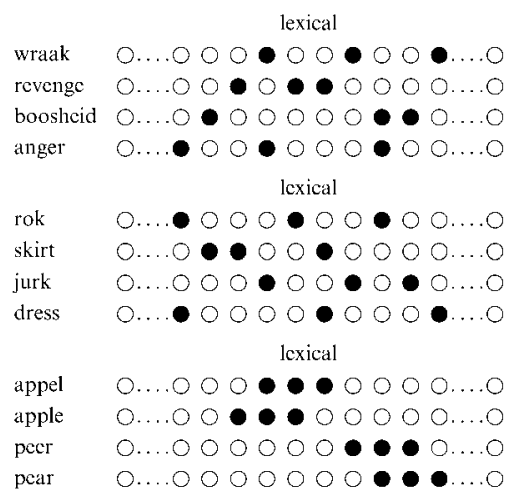

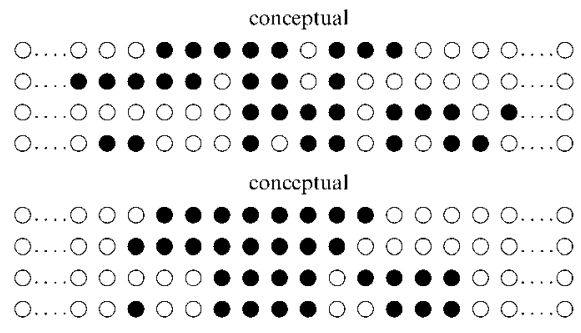

conceptual

$0 \ldots 000000 \bullet \bullet \bullet \bullet \bullet-0 \ldots 0$

$0 \ldots 000000 \bullet \bullet \bullet \bullet-00 \ldots$

$0 \ldots 0000 \bullet \bullet \bullet \bullet \bullet-0000 \ldots 0$

$0 \ldots 0000 \bullet \bullet \bullet \bullet \bullet \bullet-0000 \ldots 0$

Fig. 2. The Conceptual Feature model (English-Spanish example) as published in van Hell and de Groot (1998). Upper, middle and lower parts of the figure show distributed representations for respectively two related abstract non-cognate translation pairs, two related concrete non-cognate translation pairs, and two related concrete cognate translation pairs. Reproduced with permission of Cambridge University Press.

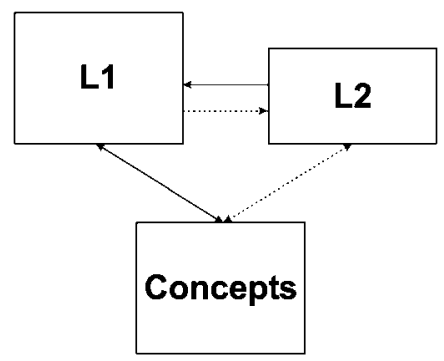

Fig. 3. The Revised Hierarchical model (RHM) of Bilingual Memory (Kroll \& Stewart 1994; Kroll \& de Groot 1997).

predicts that translation from one's second language to one's native language (backward translation) will occur through the fast and direct connections at the lexical level. No semantic access is expected to occur. Contrastingly, because the links between the L1 lexicon and semantics are much stronger than the lexical links from L1 to L2, the model predicts that forward translation (from one's native language to one's second language) requires semantic access. The RHM further assumes that this asymmetry will gradually disappear as proficiency in the second language increases.

A large number of studies have yielded empirical evidence supporting the RHM's architecture and the predictions following from it. For instance, Kroll and Stewart (1994) manipulated the semantic coherence within word lists that were presented for translation: some lists contained words from a single semantic category (e.g. fruits), whereas other lists contained words from different categories (e.g. fruits, clothes, animals). This manipulation of semantic context did not affect backward translation (translation from L2 to 
L1), but it did have an effect on forward translation (translation from L1 to L2). In the latter case, it took more time to translate words in the blocked lists than in the mixed lists. This is in line with the idea that backward translation does not go via the conceptual system, whereas forward translation requires semantic access. Also, backward translation was faster than forward translation, in line with the strong and direct lexical connections from L2 words to L1 words. In line with the predictions of the RHM concerning proficiency, Talamas et al. (1999) showed that less proficient bilinguals suffered more interference from orthographically (i.e. lexically) related foils in a translation task, whereas more proficient bilinguals performed worse on semantically (i.e. conceptually) related foils. For a more detailed review of the findings supporting the different assumptions of the RHM, we refer to Kroll and colleagues (Kroll \& de Groot 1997; Kroll \& Tokowicz 2005).

However, recently a few studies failed to support the RHM's assumption that lexical representations from the second language are not mapped directly onto semantics. First, La Heij et al. (1996) used a Stroop task, in which participants have to name the color in which color words are printed. This task is often used to show activation from semantics, because it is difficult to ignore the meaning of the word when naming the color it is printed in (e.g. it is more difficult to say 'green' when the word red is printed in green ink than when the word car is printed in green ink). La Heij et al. found that congruent color words (e.g. the word RED printed in red ink) were translated faster than incongruent color words (e.g. the word BLUE printed in red ink), in both directions of translation. This shows that both forward and backward translations (of the ink color) were influenced by the meaning of the words of which the ink color needed to be translated. Additionally, La Heij et al. also found that both forward and backward translation could be facilitated by showing pictures of objects belonging to the same semantic category as the words that needed to be translated. Second, Duyck and Brysbaert (2004) reported semantic effects of number magnitude in translation. They started from the well-known finding in the monolingual number processing domain that it takes longer to access the semantic representation of larger numbers than of smaller numbers (e.g. Brysbaert 1995). Using Dutch-French bilinguals, Duyck and Brysbaert found that it takes longer to translate number words representing larger quantities (e.g. huit [eight]) than number words representing smaller quantities (e.g. quatre [four]). Because this semantic number magnitude effect emerged in both directions of translation, this strongly suggests that both backward and forward translation may involve mandatory semantic access. Because the RHM predicts that the L2 number words should be translated through the fast and direct links with their L1 counterparts, it does not predict such a magnitude effect in backward translation. Interestingly, Duyck and Brysbaert replicated these magnitude effects with artificial number words that were learned only several minutes before the translation tasks (participants were told that some non-words were the number words in a language they did 
not know and were asked to learn them). The results for these newly learned number words contrasts with the RHM's developmental hypothesis, which states that L2 lexico-semantic mappings may only develop in very high proficiency levels. Third, a study of Altarriba and Mathis (1997) also suggests the early development of L2 lexico-semantic links. They trained a group of monolinguals on a set of English-Spanish color word pairs, which were subsequently used as translation targets in a Stroop paradigm. Similar to La Heij et al. (1996), they found that congruent color words were translated faster than incongruent color words. These studies showing semantic effects in backward translation seem to suggest that mappings from L2 lexical representations onto semantics may be stronger and develop earlier than assumed by the classical RHM.

It is clear that an integrated model of bilingual language processing will not only have to specify how lexical and semantic representations should be conceived, but also how these representations are mapped onto each other. Inspiring a lot of research, the RHM has greatly contributed to this, and is therefore a good model to build upon. However, future developments will have to take into account the recent findings discussed above. First, as can be seen in Figure 3, this classical model is not compliant with the above research on lexical representations. For example, the model still contains two separate lexicons, which is clearly at odds with the large body of evidence against lexical autonomy (see above). Second, the RHM should be more specific about the nature of semantic representations, assuming gradual semantic feature overlap depending on word variables, similar to the way semantics are conceived in the DFM (see earlier). An updated version of the RHM with these two modifications would probably look like Figure 4.

Finally, in order to deal with the findings of Altarriba and Mathis (1997), Duyck and Brysbaert (2004) and La Heij et al. (1996), any future model of lexico-semantic organization will probably have to drop the RHM's assumption that L2 lexico-semantic links may only develop in high levels of L2 proficiency. The studies above have clearly shown that, for certain types of L2 words (such as color/number words, which have clearly defined, cross-lingually largely overlapping, semantic representations), lexical representations are mapped early and strongly onto their underlying semantic representation.

However, note that the evidence for early form-to-meaning mappings contrasts with some recent studies. For instance, Kotz and Elston-Güttler (2004) studied advanced and less proficient German learners of English. Whereas these two groups of bilinguals showed some evidence for associative word priming (i.e. it was easier to recognize the word boy if they had seen the word girl, which are words that often appear together in language), they showed no categorical priming (i.e. it was not easier to recognize the word boy if they had seen the word junior before, which are words from the same category). This shows that even proficiency L2 learners may be limited in 
lexicon

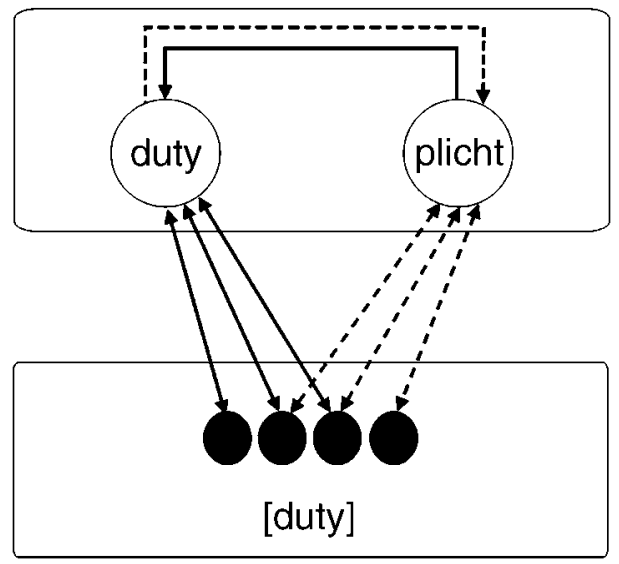

semantics

Fig. 4. The Revised Hierarchical model (RHM) with integrated lexicons and distributed semantic representations (Dutch-English stimulus example).

the degree to which they are able to access semantic representations. Similarly, using Spanish-English bilinguals, Silverberg and Samuel found semantic priming of English primes (e.g. nail) on Spanish targets (e.g. tornillo [screw]) for early bilinguals (bilinguals who learned English from a very early age), but not for late bilinguals (bilinguals who learned English at a late age), even if these late bilinguals were highly proficient. This suggests that, besides proficiency, age of acquisition may also be a crucial determinant of the way in which lexical representations from the second language interact with meaning. To conclude, this issue does not have a clear-cut, definite answer yet. To explain this apparent contradictory pattern of results, future models of bilingual lexico-semantic organization will probably have to accept the possibility that the strength and speed of development of lexico-semantic connections may vary depending on word type, cross-lingual (form/semantic) overlap, language characteristics, etc.

\section{Syntactic Representations}

Identifying words (lexical level) and understanding their meaning (semantic level) are obviously not enough for understanding language. The next step is to combine the meanings of the different words in order to understand whole utterances. For instance, whereas the sentences John kicked Paul and Paul kicked John contain the same words, they mean different things. The goal of sentence processing research is to examine the syntactic representations and processes that are used to get from the identification of words to the meaning of an entire sentence. Within bilingual language processing 
this line of research has not yet developed as substantially as the word-level research. Also, previous reviews of the bilingual psycholinguistic research were restricted to the lexical level. For these reasons, in the present review we will discuss the pioneer studies in somewhat greater detail than the lexical studies above.

\section{BILINGUALS' VS. MONOLINGUALS' SENTENCE PROCESSING}

At the syntactic level, bilingual processing was initially studied in an indirect way. Instead of investigating whether processing one language influenced processing of the other language in bilinguals (as was done in virtually every study mentioned in the word-level sections above), researchers compared syntactic processing of bilinguals with syntactic processing of monolinguals. The underlying idea is that if bilinguals process their first language differently from monolinguals of that language, then it must be that exposure to a second language influenced the processing of their native language. For instance if Spanish-English bilinguals process Spanish sentences differently compared to how Spanish monolinguals process the same sentences, it means that their knowledge of English has influenced how they process their native language. Some researchers have looked at the preferred interpretation of syntactic ambiguities and how this preferred interpretation changes under the influence of learning a second language. For instance, Fernandez (1998) and Dussias $(2003,2004)$ studied the preference for the relative clause attachment ambiguity. In this ambiguity a relative clause can be attached to two possible noun phrases.

(1) Someone shot the servant of the actress who was on the balcony.

In example (1), the relative clause who was on the balcony can relate to the noun phrase the servant or to the noun phrase the actress. The first interpretation is called $\mathrm{N} 1$ attachment (because in this case the relative clause is attached to the first potential noun phrase) and the second interpretation $\mathrm{N} 2$ attachment (because in this case the relative clause is attached to the second potential noun phrase). Cuetos and Mitchell (1988) showed that the preferred interpretation of this syntactic ambiguity differs across languages. Whereas, on average, English speakers prefer N2 attachment with this kind of sentences, Spanish speakers prefer N1 attachment. Fernandez (1998) and Dussias $(2003,2004)$ assumed that if knowing a second language can interfere with one's native language, Spanish speakers who have been exposed to English should have a higher preference for N2 attachment than Spanish speakers who have not been exposed to English. Indeed, they found that Spanish monolinguals had a lower preference for N2 attachment than Spanish-English bilinguals, even when both groups were tested with the same Spanish sentences. So these studies seem to lead to the same conclusion as the studies that focused on the word level, namely that knowing a second language has a strong influence on processing your first language. 
An important problem with this type of studies is that they rely on comparing sentence processing preferences of two entirely different groups of participants: monolinguals and bilinguals. This leads to the possibility that participants in both groups differ on other dimensions than the exposure to a second language. Recently, Swets et al. (forthcoming) have shown that individual differences in working-memory capacity can have a huge influence on syntactic ambiguity resolution preferences. For instance, people with a large working-memory capacity had a higher preference for N2 attachment than people with a smaller working-memory capacity. They showed that these individual working-memory capacity differences actually had a much larger effect on relative clause attachment preferences than the effect of language that was shown by Cuetos and Mitchell (1988). This means that if the two groups (monolinguals and bilinguals) are not carefully controlled for factors like this, their sentence processing preference might differ for other reasons than the number of languages they know.

So, even though the studies we discussed above are suggestive, it would be more insightful to have a technique that shows a more direct influence of L2 processing on L1 processing or vice versa, just as in the lexical studies above. The difficulty of designing methods to study how the activation of a syntactic structure in one language might help or interfere with the activation of a syntactic structure in another language is actually a plausible reason for why bilingualism has received less attention in syntactic research than in lexical research. The many early demonstrations that lexical characteristics (phonology, orthography, semantics, etc.) can be primed in monolingual settings (e.g. Meyer \& Schvaneveldt 1971) made it relatively easy to adapt these priming paradigms to bilingual processing research. In syntactic processing research it took until the late 1980s to show that also syntactic structures can be primed in monolinguals (Bock 1986, 1989). Evidently, this means that bilingual syntactic priming developed much later than bilingual lexical priming.

\section{SYNTACTIC PRIMING}

Bock $(1986,1989)$ demonstrated that it is possible to prime syntactic structures, i.e. she showed that participants are more likely to use a specific syntactic structure, when they had to use that same syntactic structure just before. She set up a task in which participants were presented alternately with a sentence and with a picture on a computer screen. When they were presented with a sentence, they had to read the sentence out loud. When they saw a picture, they had to describe it in their own words. Bock investigated whether the picture descriptions that participants produced (i.e. the target sentences) were influenced by the syntactic structure of the sentences they had to read out loud (i.e. the prime sentences). The sentences and the pictures were semantically unrelated so that any influence could only be attributed to the syntactic structure of the sentences. First, she studied 
active and passive sentence structures as in (2). Both alternatives (2a and 2b) have the same meaning, but a different syntactic structure.

(2a) Active prime sentence

The fan punched the referee.

(2b) Passive prime sentence

The referee was punched by the fan.

Bock (1986) found that the likelihood of describing the picture using a passive sentence structure increased when they had just read a passive prime sentence compared to when they had just read an active prime sentence. For instance, when they saw a picture of a nun that was being mugged by a teenager, they were more likely to say something like The nun is being mugged by a teenager instead of The teenager is mugging the nun when they had just read a passive sentence like (2b) compared to when they had just read an active sentence like (2a).

Second, she also studied sentences with dative verbs that allow two alternative syntactic structures as in (3). Dative verbs are verbs that take a direct object and an indirect object. In the first alternative (see 3a), the indirect object comes last and is realized by a prepositional phrase (to the woman). This alternative is called a prepositional-object dative construction. In the second alternative (see $3 b$ ), the indirect object comes first and is realized as a noun phrase (the woman). This alternative is called a doubleobject dative construction. Again, both alternatives have the same meaning, but a different syntactic structure.

(3a) Prepositional-object dative prime

The baker gave the bread to the woman.

(3b) Double-object dative prime

The baker gave the woman the bread.

Similarly as with the active-passive alternatives, the likelihood that participants described a picture using a double-object construction increased when they had just read a sentence that contained a double-object construction compared to when they had just read a sentence that contained a prepositionalobject construction. For instance, when they were presented with a picture of a girl giving a paintbrush to a man, participants were more likely to say The girl handed the man the paintbrush instead of The girl handed the paintbrush to the man following a double-object dative prime sentence as in (3b) than following a prepositional-object dative prime sentence as in $(3 c)$.

Very recently, this syntactic priming technique was adapted to bilingual research to investigate the syntactic representations that are used by bilinguals. Loebell and Bock (2003) used the same picture-description task with fluent German-English bilinguals. These bilinguals were asked to repeat a sentence in either their first (German) or their second language (English) and then to describe an unrelated picture in the other language. Loebell and Bock used the same constructions as Bock (1986), namely, the dative alternatives 
(double-object $v$ s. prepositional-object datives) and the transitive alternatives (active $v$ s. passive sentences). After being primed with a prepositional-object construction, participants were more likely to describe the picture with a proposition-object construction. They obtained similar priming effects with the double-object construction (more double-object picture descriptions following a double-object sentence) and with active sentences (more active picture descriptions following an active sentence). However, the passive constructions did not show any syntactic priming effect. Loebell and Bock explain this finding by pointing out that in the case of passive sentences the structure in German and English differ slightly. Whereas the verb is placed at the end of the sentence in German (e.g. Die Böden werden täglich von dem Hausmeister gereinigt, literally [The floors are daily by the janitor cleaned]), this is not true in English (e.g. The floors are cleaned daily by the janitor). In line with this explanation, Hartsuiker, Pickering andVeltkamp (2004) found that when the passives are more similar in structure between the two languages, such as in English and Spanish, this structure can be primed cross-linguistically. They tested naïve bilingual participants who were primed by a confederate of the experimenters. The experiment consisted of a version of the picture-description task in which the confederate-described pictures in Spanish and the naive participant consecutively had to describe pictures in English. Hartsuiker et al. showed that the participants were more likely to use an active sentence in English when the confederate had just used an active sentence in Spanish. More crucially, the same was found for passives: when the confederate used a passive sentence in Spanish, the participants were more likely to use a passive in English as well.

The fact that Hartsuiker et al. (2004) found priming of passives between English and Spanish, whereas Loebell and Bock (2003) did not between English and German, seems to suggest that the word order of the passive construction needs to be the same in both languages in order to obtain priming. In a recent study, Bernolet, Hartsuiker and Pickering (forthcoming) investigated whether the word order is also crucial for cross-lingual priming in other constructions. Using the picture-description paradigm, they investigated the production of post-nominal modifiers (modifiers that follow the noun, such as relative clauses, e.g. the shark that is red) vs. pre-nominal modifiers (modifiers that precede the noun, such as adjectives, e.g. the red shark) in Dutch-English bilinguals. In Dutch, the post-nominal modifier (e.g. de haai die rood is [the shark that red is]) has a slightly different word order than English (e.g. the shark that is red). If word order is crucial for priming, then it should be possible to obtain significant priming effects within a language, but not between languages. This is exactly the pattern of results that was obtained by Bernolet et al. They found significant priming with post-nominal modifiers from Dutch to Dutch and from English to English. However, they did not find priming from English to Dutch or from Dutch to English. 
What these studies have demonstrated is the existence of cross-linguistic syntactic priming: the languages of a bilingual can influence each other at the syntactic level, as long as the syntactic constructions are similar enough. So just as in the word-level domain, this means that syntactic information of one language is activate when processing syntactic information of the other language. However, the syntactic information that is being primed is very closely related to specific lexical representations (words). For instance, only a few specific verbs (such as give, lend, post, hand, etc.) allow for the two alternative dative constructions (the double-object and prepositionalobject dative). With most other verbs it is not possible to form double-object or prepositional-object sentences. The same can be said for most of the other syntactic constructions mentioned above: the syntactic information that interacts between the two languages of a bilingual is strongly associated with lexical items. Some psycholinguists therefore say that the studies above have shown interactions of lexical information across languages (just as the studies in the previous section) and not really interactions of syntactic information across languages. A strong piece of evidence that the syntactic information that is being primed is closely tied to the lexical entry of the verbs is the 'lexical boost' effect. Pickering and Branigan (1998) showed that the syntactic priming effect in monolingual research is much larger when the prime and target sentence contain the same verb than when the prime and target sentence contain different verbs. Very interestingly, Schoonbaert, Hartsuiker and Pickering (2005) showed that the same holds for bilingual syntactic priming. They showed that the priming effect of the dative constructions from English to Dutch in Dutch-English bilinguals was much stronger when the prime and target contained translations of the same verb (e.g. give in the English prime and geven [give] in the Dutch target) than when the prime and target contained different verbs (e.g. give in the English prime and aanreiken [hand] in the Dutch target). Given that the orthographic, phonological and semantic information at the lexical level from the two languages of bilinguals interact with each other, it is not surprising (but still interesting) that this also holds for syntactic information at the lexical level.

However, in a more recent article, Desmet and Declercq (2006) have investigated whether syntactic information that is not related to specific lexical entries can also be primed between the two languages of bilinguals. The structure that they investigated was the relative clause attachment ambiguity, which was presented in example (1). In this ambiguity, the relative clause can either be attached to a first noun phrase ( $\mathrm{N} 1$ attachment) or a second noun phrase (N2 attachment). Unlike the prepositional-object $v s$. double-object syntactic structure, which can only be formed with very specific verbs (e.g. give, send), the N1 attachment $v$ s. N2 attachment syntactic structure is not restricted to specific words. Every noun can be modified by a relative clause. So, the syntactic information that is being studied here is a high-level, abstract type of syntactic representation that is quite remote from the specific words that are used (see their article for a detailed discussion 
of this point). Desmet and Declercq (2006) studied whether these syntactic alternatives could be primed between the languages of proficient DutchEnglish bilinguals. They presented a sentence completion task where participants had to complete sentence beginnings. The English target sentence beginnings always ended in an ambiguous relative pronoun.

(3) John met the boss of the employees who ...

In example (3), the relative pronoun who can refer to the boss or to the employees, so participants are completely free to produce a relative clause that attaches to N1 or N2. Before each target sentence beginning, participants had to complete a prime sentence beginning that forced one attachment. This was done by using gender cues on the relative pronoun in Dutch.

(4) Maria troostte het kindje van de medebewoonster dat

[Maria consoled the child of the roommate who]

(5) Maria troostte het kindje van de medebewoonster die

[Maria consoled the child of the roommate who]

In the N1 attachment prime example (4), the relative pronoun dat in Dutch can only refer to a noun that takes the determiner het, so participants are forced to produce a relative clause that refers to the first noun phrase het kindje [the child] and not to the second noun phrase de medebewoonster [the roommate]. In the N2 attachment prime example (5), the relative pronoun die in Dutch can only refer to a noun that takes the determiner de, so participants are forced to produce a relative clause that refers to the second noun phrase de medebewoonster [the roommate] and not to the first noun phrase het kindje [the child]. Desmet and Declercq showed that people were more likely to produce N1 attachments in the ambiguous English target sentences, when they had been forced to produce a Dutch N1 attachment in the prime compared to when they had been forced to produce a Dutch $\mathrm{N} 2$ attachment in the prime. This means that not only lexically represented syntactic frames, but also more abstract syntactic configurations can be primed between the two languages of bilinguals. In a new study, Desmet and Devuyst (forthcoming) show that not only the syntax of the native language (Dutch) can have an effect on the syntax of the second language (English) as Desmet and Declercq (2006) showed, but also that the second language (English) can interfere with the native language (Dutch).

Although the number of bilingual studies on sentence processing is still rather scarce at this point, it seems already clear that learning a second language influences the processing of the first language. This influence does not only have an immediate effect, as is clear from the bilingual syntactic priming studies, but probably also has an effect in the long run, as the studies comparing bilinguals and monolinguals suggest. Moreover, the interaction between the different languages of bilinguals seems to happen across a wide range of syntactic structures, form lexically represented syntactic frames to abstract syntactic configurations. Given the many similarities in syntactic 
structures across languages (e.g. Greenberg 1966; Chomsky 1981; Hawkins 1988), this has led several researchers to suggest that bilinguals may take advantage of these similarities by representing these syntactic structures only once or by representing them in a highly integrated way (e.g. Desmet \& Declercq 2006; Desmet \& Devuyst, forthcoming; Hartsuiker et al. 2004). A lot of further research is needed, however, in order to evaluate this so-called 'shared-syntax' account of bilingual sentence processing. One challenge for future research will be to find out the exact nature of the representations and processes that are shared between languages. It seems to be the case, for instance, that in order to obtain an influence from L2 to L1, the syntactic structures need to have the same word order in both languages. Further research will have to find out whether this is always true and many questions remain unanswered about how different or similar the structures need to be across languages in order to find interference from one language to the other. Another important challenge within syntactic bilingual language processing will be to find out whether the long-term effects that we discussed in the beginning of the section are driven by the same mechanisms underlying the short-term changes in activation that have been shown in the syntactic priming studies. Finally, as in the research on bilingual lexical processing, it will be of importance to find out how the interaction between the syntactic representations of the two languages is affected by the proficiency of the bilinguals (e.g. Hahne \& Friederici 2001).

\section{Language Control and Switching}

The recurring theme throughout the previous sections is clearly the fact that both languages of a bilingual constantly seem to interact at different representational levels. In this view, one may wonder how a bilingual actually manages to process unilingual language without too much cross-lingual intrusions and errors, as most bilinguals eventually can. This question is especially important for production. In recognition, a bilingual is confronted with input in a given language, and there is no compelling need for an early language selection mechanism. In production, however, the output language has to be selected at a certain point before the actual word is produced (because you do not want to produce a French word while speaking English).

There is a consensus that at least some stages of the word production process are not language specific. Evidence for this claim comes for instance from Hermans et al. (1998). Studying English-Dutch bilinguals, they found that the production of English words to describe a picture (e.g. mountain) was inhibited when a Dutch word appeared (and needed to be ignored) that was phonologically related to the target's translation (e.g. berm which has the same onset as berg [mountain]). This shows that lexical representations from the native language become activated to a certain degree in a production task that is exclusively in the second language. Similar evidence comes from Costa et al. (2000). They found that Spanish-English bilinguals 
were faster to name pictures in English when the picture names were cognates (e.g. guitar-guitarra) than when they were not cognates. They attributed this to the fact that for cognates, the phonological segments of the target word receive activation both from the target's lexical representation, and from its translation equivalent in the non-response language. In this view, it is also interesting to note that Gollan and Acenas (2004) showed that bilinguals have more tip-of-the-tongue states than monolingual speakers, caused by unresolved production selection processes due to crosslingual interference. So, the important remaining question is not whether production is language selective but when the language selection occurs.

The dominant model of bilingual word production is that of Poulisse and Bongaerts (1994). Similar to monolingual production models (e.g. Levelt 1989), the model postulates three levels to convey meaning through spoken words: the conceptual level, the lemma level and the phonological level. Basically, in order to say a word, you need to know what you want to say (conceptual level), you need to select the right word (lemma level), and you need to know how to pronounce the word (phonological level). Whereas earlier production research situated the language selection mechanism at the lemma selection level (e.g. Hermans et al. 1998), more recent research seems to suggest that activation in non-target language representations may be present up to the phonological level (Costa et al. 2000; Colome 2001). Others claim that the locus of language selection is not fixed, but varies depending on factors such as proficiency and task demands (Kroll, Bobb \& Wodniecka 2006). This issue, however, is beyond the scope of this article.

Some researchers have proposed that this language selection process in production is controlled by an external system that controls the competition within the different representational levels. In the Inhibitory Control model of Green (1986, 1998), for example, language selection is achieved by suppressing the lexical representations belonging to the non-target language. The most compelling evidence for such an inhibitory process comes from code switching experiments, in which participants have to randomly switch from their native language to their second language, and vice versa. Using such a paradigm, Meuter and Allport (1999) showed that it is harder for bilinguals to switch from their second language to their first language than the other way around. The explanation for this finding is that when switching from your second language to your first language, one has to overcome the massive inhibition that was needed to first suppress the more dominant native language. Interestingly, other studies (Costa \& Santesteban 2004) observed symmetrical rather than asymmetrical switching costs in highly proficient bilinguals. Because this switching cost was also symmetrical for a much weaker third language of these balanced L1/L2 bilinguals, Costa and Santesteban argued that highly proficient bilinguals acquire an early language selection mechanism, which allows then to efficiently manipulate their language output without the inhibition processes proposed by Meuter and Allport (1999). Interestingly, it has also been shown that bilinguals 
consistently outperform monolinguals in non-language-related tasks, which require cognitive control, such as making eye movements to the opposite side of the computer screen when an asterisk appears on one side of the screen (for an overview, see Bialystok 2005).

Of course, this is only a short introduction to what may be one of the main (but complex) issues for future bilingual research. For a more detailed discussion about language selection and cognitive control in bilingual production, we refer to Costa (2005), La Heij (2005) and the special speech production control issue of Bilingualism: Language and Cognition (vol. 9, no. 2, 2006).

\section{Conclusions}

In this article, we provided a brief review of the psycholinguistic research that has been done to uncover the processes and representations that bilinguals use when they are processing language. The main conclusion from an overview of the different representational levels that have been studied (the lexical level, the semantic level, and the syntactic level) is that the different languages of bilinguals strongly interact during processing. Bilingual speakers and listeners seem to take advantage of the many universal characteristics between the languages they know, by representing their languages in a highly integrated way. In line with this conclusion, from a short overview of some recent research on language control and language switching, it seems that keeping interference from the different languages under control comes with a small but measurable cognitive cost.

\section{Acknowledgments}

Timothy Desmet and Wouter Duyck are postdoctoral fellows of the Research Foundation - Flanders (FWO, Vlaanderen). We would like to thank Judy Kroll and an anonymous reviewer for comments on an earlier version of this article.

\section{Short Biographies}

Timothy Desmet is a Postdoctoral Fellow of the Research Foundation Flanders at the Department of Experimental Psychology of Ghent University, Belgium. His research deals with the cognitive processes and representations used in sentence comprehension and production. He is mainly investigating research questions related to syntactic ambiguity resolution, the correspondence between sentence comprehension and production, the role of syntactic frequency, and the role of working memory in language processes. More recently, he has studied how the sentence structures of the two languages of bilinguals interact with each other (e.g. Desmet \& Declercq, 2006, Journal of Memory and Language). He received his Licentiate and Ph.D. 
from Ghent University, and spent extensive research visits at the Massachusetts Institute of Technology and Michigan State University.

Wouter Duyck is currently working as a post-doctoral research fellow of the Research Foundation Flanders at the Department of Experimental Psychology, Ghent, Belgium. He holds a MA and a Ph.D from Ghent University, Belgium. For his dissertation, he received the triennial Prix de Psychologie of the Royal Academy of Science, Humanities and Fine Arts of Belgium. He has mainly authored or co-authored papers on language processing by bilinguals, most of which focussed on visual word recognition or translation. Other research interests include working memory, word/ language acquisition and number processing. Forthcoming articles will discuss the influence of sentence contexts on word recognition by bilinguals.

\section{Endnote}

^ Correspondence address: Timothy Desmet, Department of Experimental Psychology, Ghent University, Henri Dunantlaan 2, B-9000 Gent, Belgium.

\section{Works Cited}

Altarriba, J. 2003. Does carińo equal 'liking'? A theoretical approach to conceptual nonequivalence between languages. International Journal of Bilingualism 7.305-22.

Altarriba, J., and K. M. Mathis. 1997. Conceptual and lexical development in second language acquisition. Journal of Memory and Language 36.550-68.

Bamgbose, A. 1994. Nigeria's choice. UNESCO Courier. 22-31.

Bernolet, S., Hartsuiker, R. J., \& Pickering, M. J. (forthcoming). Word order and language production in bilinguals: evidence from syntactic priming.

Bialystok, E. 2005. Consequences of bilingualism for cognitive development. Handbook of bilingualism: Psycholinguistic approaches, ed. by J. F. Kroll and A. M. B. de Groot, 417-32. New York: Oxford University Press.

Bock, J. K. 1986. Syntactic persistence in language production. Cognitive Psychology 18.355-87. . 1989. Closed class immanence in sentence production. Cognition 31.163-86.

Brysbaert, M. 1995. Arabic number reading-on the nature of the numerical scale and the origin of phonological recoding. Journal of Experimental Psychology: General 124.434-52.

Brysbaert, M., G. Van Dyck, and M.Van de Poel. 1999. Visual word recognition in bilinguals: evidence from masked phonological priming. Journal of Experimental Psychology: Human Perception and Performance 25.137-48.

Caramazza, A., and I. Brones. 1979. Lexical access in bilinguals. Bulletin of the Psychonomic Society 13.212-4.

Chomsky, N. 1981. Lectures on government and binding. Dordrecht, The Netherlands: Foris.

Colome, A. 2001. Lexical activation in bilinguals' speech production: language-specific or language-independent? Journal of Memory and Language 45.721-36.

Costa, A. 2005. Lexical access in bilingual production. Handbook of bilingualism: Psycholinguistic approaches, ed. by J. F. Kroll and A. M. B. de Groot, 308-25. New York: Oxford University Press.

Costa, A., and M. Santesteban. 2004. Lexical access in bilingual speech production: evidence from language switching in highly proficient bilinguals and L2 learners. Journal of Memory and Language 50.491-511.

Costa, A., A. Caramazza, and N. Sebastian-Galles. 2000. The cognate facilitation effect: implications for models of lexical access. Journal of Experimental Psychology: Learning Memory and Cognition 26.1283-96.

Costa, A., M. Miozzo, and A. Caramazza. 1999. Lexical selection in bilinguals: do words in the bilingual's two lexicons compete for selection? Journal of Memory and Language 41.365-97.

(C) 2007 The Authors Language and Linguistics Compass 1/3 (2007): 168-194, 10.1111/j.1749-818x.2007.00008.x Journal Compilation (c) 2007 Blackwell Publishing Ltd 
Costa, A., M. Santesteban, and A. Cano. 2005. On the facilitatory effects of cognate words in bilingual speech production. Brain and Language 94.94-103.

Cristoffanini, P., K. Kirsner, and D. Milech. 1986. Bilingual lexical representation - the status of Spanish-English cognates. Quarterly Journal of Experimental Psychology: Section A - Human Experimental Psychology 38.367-93.

Cuetos, F., and D. C. Mitchell. 1988. Cross-linguistic differences in parsing: restrictions on the use of the Late Closure strategy in Spanish. Cognition 30.73-105.

de Groot, A. M. B. 1992. Determinants of word translation. Journal of Experimental Psychology: Learning Memory and Cognition 18.1001-18.

de Groot, A. M. B., and G. L. J. Nas. 1991. Lexical representation of cognates and noncognates in compound bilinguals. Journal of Memory and Language 30.90-123.

de Groot, A. M. B., L. Dannenburg, and J. G. van Hell. 1994. Forward and backward word translation by bilinguals. Journal of Memory and Language 33.600-29.

Desmet, T., and M. Declercq. 2006. Cross-linguistic priming of syntactic hierarchical configuration information. Journal of Memory and Language 54.610-32.

Desmet, T., and A. Devuyst. (forthcoming). Cross-linguistic syntactic priming of RC attachments.

Dijkstra, T., and W. Van Heuven. 2002. The architecture of the bilingual word recognition system: from identification to decision. Bilingualism: Language and Cognition 5.175-97.

Dijkstra, T., E. De Bruijn, H. Schriefers, and S. Ten Brinke. 2000. More on interlingual homograph recognition: language intermixing versus explicitness of instruction. Bilingualism: Language and Cognition 3.69-78.

Dijkstra, T., J. Grainger, and W. J. B. Van Heuven. 1999. Recognition of cognates and interlingual homographs: the neglected role of phonology. Journal of Memory and Language 41.496-518.

Dijkstra, T., M. Timmermans, and H. Schriefers. 2000. On being blinded by your other language: effects of task demands on interlingual homograph recognition. Journal of Memory and Language 42.445-64.

Dussias, P. E. 2003. Syntactic ambiguity resolution in L2 learners: some effects of bilinguality on L1 and L2 processing strategies. Studies in Second Language Acquisition 25.529-57.

- 2004. Parsing a first language like a second: the erosion of L1 parsing strategies in Spanish-English bilinguals. International Journal of Bilingualism 8.355-71.

Duyck, W. 2005. Translation and associative priming with cross-lingual pseudohomophones: evidence for nonselective phonological activation in bilinguals. Journal of Experimental Psychology: Learning Memory and Cognition 31.1340-59.

Duyck, W., and M. Brysbaert. 2004. Forward and backward number translation requires conceptual mediation in both balanced and unbalanced bilinguals. Journal of Experimental Psychology: Human Perception and Performance 30.889-906.

Duyck W., E.Van Assche, and R. Hartsuiker. (forthcoming). Visual word recognition by bilinguals in a sentence context: evidence for non-selective lexical access.

Duyck, W., K. Diependaele, D. Drieghe, and M. Brysbaert. 2004. The size of the cross-lingual masked phonological priming effect does not depend on second language proficiency. Experimental Psychology 51.1-9.

Elston-Guttler, K. E., T. C. Gunter, and S. A. Kotz. 2005. Zooming into L2: global language context and adjustment affect processing of interlingual homographs in sentences. Cognitive Brain Research 25.57-70.

Fernandez,E. M. 1998. Language dependency in parsing: evidence from monolingual and bilingual processing. Psychologica Belgica 38.197-229.

Fox, E. 1996. Cross-language priming from ignored words: evidence for a common representational system in bilinguals. Journal of Memory and Language 35.353-70.

Francis, W. S. 1999. Cognitive integration of language and memory in bilinguals: semantic representation. Psychological Bulletin 125.193-222.

- 2005. Bilingual semantic and conceptual representation. Handbook of bilingualism: Psycholinguistic approaches, ed. by J. F. Kroll and A. M. B. de Groot, 251-67. New York: Oxford University Press.

Gollan, T. H., and L. A. R. Acenas. 2004. What is a tot? Cognate and translation effects on tip-of-the-tongue states in Spanish-English and Tagalog-English bilinguals. Journal of Experimental Psychology: Learning Memory and Cognition 30.246-69. 
Gollan, T. H., K. I. Forster, and R. Frost. 1997. Translation priming with different scripts: masked priming with cognates and noncognates in Hebrew-English bilinguals. Journal of Experimental Psychology: Learning Memory and Cognition 23.1122-39.

Grainger, J., and Frenck-Mestre, C. 1998. Masked priming by translation equivalents in proficient bilinguals. Language and Cognitive Processes 13.601-23.

Green, D. 1986. Control, activation, and resource: a framework and a model for the contol of speech in bilinguals. Brain and Language 27.210-23.

. 1998. Mental control of the bilingual lexico-semantic system. Bilingualism: Language and Cognition 1.67-81.

Greenberg, J. H. 1966. Universals of language. Cambridge, MA: MIT Press.

Grosjean, F. 1982. Life with two languages: An introduction to bilingualism. Cambridge, MA: Harvard University Press.

1992. Another view of bilingualism. Cognitive processing in bilinguals, ed. by R. Harris, 51-62. Amsterdam: Elsevier.

Hahne, A., and A. D. Friederici. 2001. Processing a second language: Late learners' comprehension mechanisms as revealed by event-related brain potentials. Bilingualism: Language and Cognition 4.123-41.

Hartsuiker, R. J., M. J. Pickering, and E. Veltkamp. 2004. Is syntax separate or shared between languages? Psychological Science 15.409-14.

Hawkins, J. A. 1988. Explaining language universals. Oxford, UK: Blackwell.

Hermans, D., T. Bongaerts, K. De Bot, and R. Schreuder. 1998. Producing words in a foreign language: Can speakers prevent interference from their first language? Bilingualism: Language and Cognition 1.213-29.

Illes, J., W. S. Francis, J. E. Desmond, J. D. E. Gabrieli, G. H. Gover, R. Poldrack, C. J. Lee, and A. D. Wagner. 1999. Convergent cortical representation of semantic processing in bilinguals. Brain and Language 70.347-63.

Jared, D., and J. F. Kroll. 2001. Do bilinguals activate phonological representations in one or both of their languages when naming words? Journal of Memory and Language 44.2-31.

Ju, M., and Luce, P. A. 2004. Falling on sensitive ears - Constraints on bilingual lexical activation. Psychological Science 15.314-18.

Kotz, S. A., and Elston-Guttler, K. 2004. The role of proficiency on processing categorical and associative information in the L2 as revealed by reaction times and event-related brain potentials. Journal of Neurolinguistics 17.215-35.

Kroll,J. F., and A. M. B. de Groot. 1997. Lexical and conceptual memory in the bilingual: mapping form to meaning in two languages. Tutorials in bilingualism: Psycholinguistic perspectives, ed. by. A. M. B. de Groot and J. F. Kroll, 201-24. Mahwah, NJ: Lawrence Erlbaum Publishers.

Kroll, J. F., and P. Dussias. (forthcoming). The comprehension of words and sentences in two languages. Handbook of bilingualism, ed. by T. Bhatia and W. Ritchie. Cambridge, MA: Blackwell Publishers.

Kroll, J. F., and E. Stewart. 1994. Category interference in translation and picture naming-evidence for asymmetric connections between bilingual memory representations. Journal of Memory and Language 33.149-74.

Kroll, J. F., and N. Tokowicz. 2005. Models of bilingual representation and processing: looking back and to the future. Handbook of bilingualism: Psycholinguistic approaches, ed. by J. F. Kroll and A. M. B. de Groot, 531-53. New York: Oxford University Press.

Kroll, J. F., S. C. Bobb, and Wodniecka, Z. 2006. Language selectivity is the exception, not the rule: arguments against a fixed locus of language selection in bilingual speech. Bilingualism: Language and Cognition 9.119-35.

La Heij, W. 2005. Selection processes in monolingual and bilingual lexical access. Handbook of bilingualism: Psycholinguistic approaches, ed. by J. F. Kroll and A. M. B. de Groot, 289-307. New York: Oxford University Press.

La Heij, W., A. Hooglander, R. Kerling, and E. Van der Velden. 1996. Nonverbal context effects in forward and backward word translation: evidence for concept mediation. Journal of Memory and Language 35.648-65.

Lemhöfer, K., T. Dijkstra, and M. C. Michel. 2004. Three languages, one echo: cognate effects in trilingual word recognition. Language and Cognitive Processes 19.585-611.

Levelt, W. J. M. 1989. Speaking: From intention to articulation. Cambridge, MA: Bradford. 
Loebell, H., and K. Bock. 2003. Structural priming across languages. Linguistics 41.791-824.

Marian, V., M. Spivey, and J. Hirsch. 2003. Shared and separate systems in bilingual language processing: converging evidence from eyetracking and brain imaging. Brain and Language 86.70-82.

McClelland, J. L., and D. E. Rumelhart. 1981. An interactive activation model of context effects in letter perception: an account of basic findings. Psychological Review 88.375-407.

Meuter, R. F. I., and A. Allport. 1999. Bilingual language switching in naming: asymmetrical costs of language selection. Journal of Memory and Language 40.25-40.

Meyer, D. E., and R.W. Schvaneveldt. 1971. Facilitation in recognizing pairs of words: Evidence of a dependence between retrieval operations. Journal of Experimental Psychology 90.227-34.

Pickering, M. J., and H. P. Branigan. 1998. The representation of verbs: evidence from syntactic priming in language production. Journal of Memory and Language 39.633-51.

Poulisse, N., and T. Bongaerts. 1994. 1st language use in 2nd-language production. Applied Linguistics $15.36-57$.

Sánchez-Casas, R. M., C. W. Davis, and J. E. Garcia-Albea. 1992. Bilingual lexical processing-exploring the cognate non-cognate distinction. European Journal of Cognitive Psychology 4.293-310.

Schoonbaert, S., R. J. Hartsuiker, and M. J. Pickering. 2005. The representation of lexical and syntactic information in bilinguals: Evidence from syntactic priming. Journal of Memory and Language 56.153-71.

Schwanenflugel, P. J., and K. L. Lacount. 1988. Semantic relatedness and the scope of facilitation for upcoming words in sentences. Journal of Experimental Psychology: Learning Memory and Cognition 14.344-54.

Schwartz, A. I., and J. F. Kroll. 2006. Bilingual lexical activation in sentence context. Journal of Memory and Language 55.197-212.

Schwartz, A. I., J. F. Kroll, and M. Diaz. (forthcoming). Reading words in Spanish and English: mapping orthography to phonology in two languages. Language and Cognitive Processes.

Swets, B., T. Desmet, D. Z. Hambrick, and F. Ferreira. (forthcoming). The role of working memory in syntactic ambiguity resolution: a psychometric approach. Journal of Experimental Psychology: General.

Talamas, A., J. F. Kroll, and R. Dufour. 1999. From form to meaning: stages in the acquisition of second-language vocabulary. Bilingualism: Language and Cognition 2.45-58.

Thomas, M. S. C., and W. J. B. Van Heuven. 2005. Computational models of bilingual comprehension. Handbook of bilingualism: Psycholinguistic approaches, ed. by J. F. Kroll and A. M. B. de Groot. New York: Oxford University Press.

van Hell, J. G., and A. M. B. de Groot. 1998. Conceptual representation in bilingual memory: effects of concreteness and cognate status in word association. Bilingualism: Language and Cognition 1.193-211.

Van Hell, J. G., and T. Dijkstra. 2002. Foreign language knowledge can influence native language performance in exclusively native contexts. Psychonomic Bulletin \& Review 9.780-9.

Van Heuven, W. J. B., A. Dijkstra, and J. Grainger. 1998. Orthographic neighborhood effects in bilingual word recognition. Journal of Memory and Language 39.458-83.

Van Wijnendaele, I., and M. Brysbaert. 2002. Visual word recognition in bilinguals: phonological priming from the second to the first language. Journal of Experimental Psychology: Human Perception and Performance 28.616-27.

Weber, A., and A. Cutler. 2004. Lexical competition in non-native spoken-word recognition. Journal of Memory and Language 50.1-25. 